\title{
Late aneurysm formation with destruction of the left lung after subclavian flap angioplasty for coarctation of aorta
}

\author{
Sanjay Theodore, MS, ${ }^{a}$ Praveen Kerala Varma, $\mathrm{MCh}^{,}{ }^{a}$ Praveen Kumar Neema, MD, ${ }^{\mathrm{b}}$ and \\ Kurur Sankaran Neelakandhan, $\mathrm{MCh},{ }^{a}$ Kerala, India
}

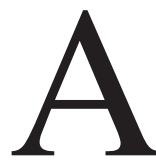

neurysm formation after prosthetic patch repair of coarctation of the aorta was a frequent complication that resulted in abandonment of the procedure. Subclavian flap angioplasty (SFA) was popularized in the 1960s, primarily to prevent late recoarctation. ${ }^{1}$ However, late aneurysm formation after SFA has been reported in at least 6 cases. $^{2}$

\section{Clinical Summary}

A 21-year-old woman presented with New York Heart Association class III symptoms and recurrent respiratory tract infection for 1 year. She had repair of juxtaductal coarctation of the aorta with SFA at 3 years of age. General physical examination of the patient was unremarkable, except for the absence of air entry on the left side of the chest. The left chest wall was deformed. Her blood pressures in the right arm and lower limbs were 110/70 and 120/80 $\mathrm{mm} \mathrm{Hg}$, respectively. The left radial and brachial pulse was absent, and chest radiography revealed opacity over the left hemithorax, with no visible lung markings (Figure 1). Computed tomography showed a large saccular aneurysm with thrombus arising just distal to the left common carotid artery and destroyed left lung (Figure 2 ). The surgical approach was through midline sternotomy, and an anterolateral thoracotomy was made through the fourth intercostal space, converting the incisions into a $\mathrm{T}$ shape. Cardiopulmonary bypass was established after aortic cannulation and a single 2 -stage venous cannulation. In addition, a femoral arterial cannula was also inserted to perfuse retrogradely during clamping of the aorta and repair of the aneurysm. The aneurysm was adherent to the chest wall and the lung. The lung was dissected away from the aneurysm. It was thin, fibrotic, and totally destroyed, and it could not be reinflated. Therefore pneumonectomy was performed. The aneurysm measured $10 \mathrm{~cm} \times 7 \mathrm{~cm} \times 7 \mathrm{~cm}$. The aorta was clamped distal to the left common carotid artery and at the diaphragm. The aneurysm was opened, and a $3 \mathrm{~cm} \times 4 \mathrm{~cm}$ neck was identified, which was communicating with the descending thoracic aorta and

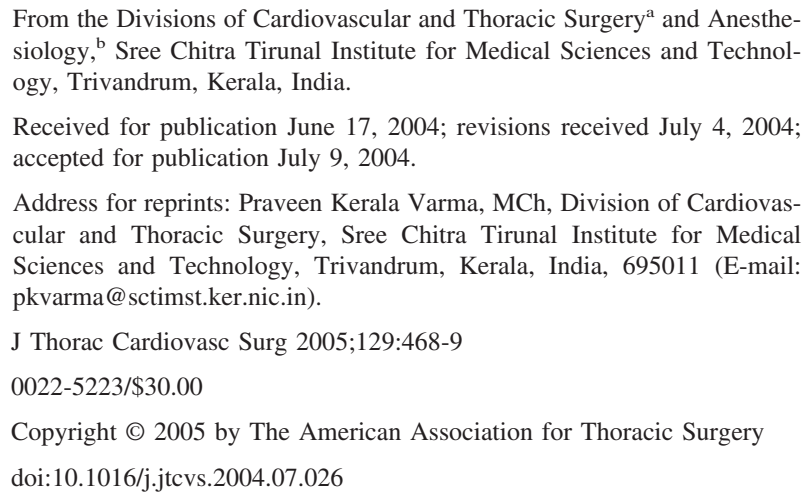

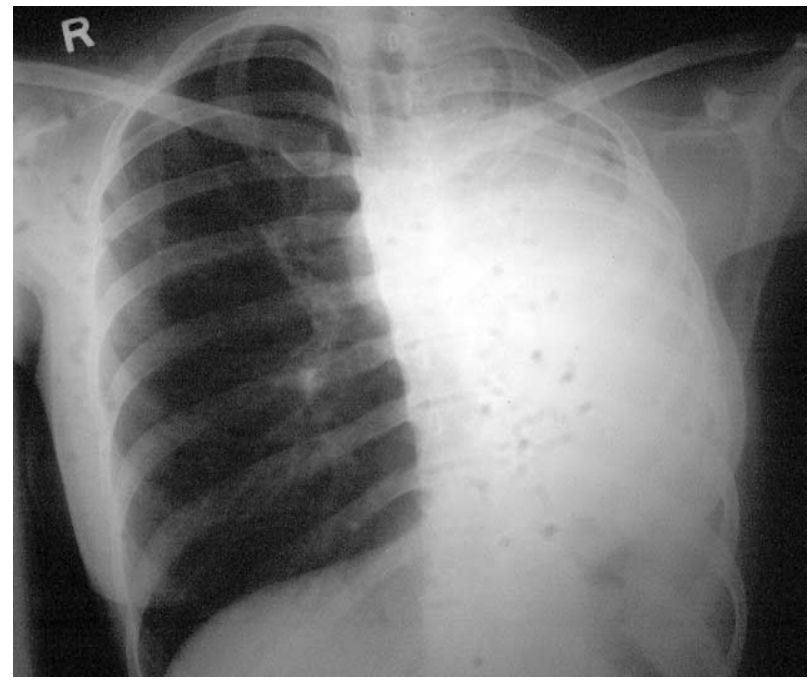

Figure 1. Chest x-ray film showing opacity of left hemithorax, absent left-lung markings, and compensatory emphysema of the right lung.

was closed with a Dacron patch. After surgical repair, the patient was weaned off bypass; there was significant hemorrhage from the left pulmonary artery that was repaired after re-establishment of cardiopulmonary bypass. However, the patient continued to bleed in the postoperative period and later died on the second postoperative day.

\section{Discussion}

The aneurysm formation after coarctation repair can be true or false. The true aneurysm is known to occur opposite of the prosthetic patch, ${ }^{1}$ whereas false aneurysms are generally caused by suture line leaks, technical problems, and infection. Moulten and colleagues $^{3}$ suggested that any kind of patch in the aortic position is predisposed to aneurysm formation because abnormal ductal tissue remains after both SFA and prosthetic patch repair. However, Mellgren and asociates, ${ }^{4}$ after extensive studies in a pig model, concluded that the subclavian flap was living tissue that was well suited to function in the aortic position. True aneurysms are rare after SFA, with only 6 cases reported. ${ }^{2}$ In our case the aneurysm was detected 18 years after the primary operation and was at the site of the previous patch angioplasty. Other reports also suggest that the aneurysm arises from the site of SFA. ${ }^{2}$ Interestingly, unlike the aneurysm formation after prosthetic patch plasty that occurs opposite the site of the patch, all reported cases of aneurysm after SFA have occurred in the region of the flap. The subclavian flap is subjected to 3 to 4 times the stress it normally 


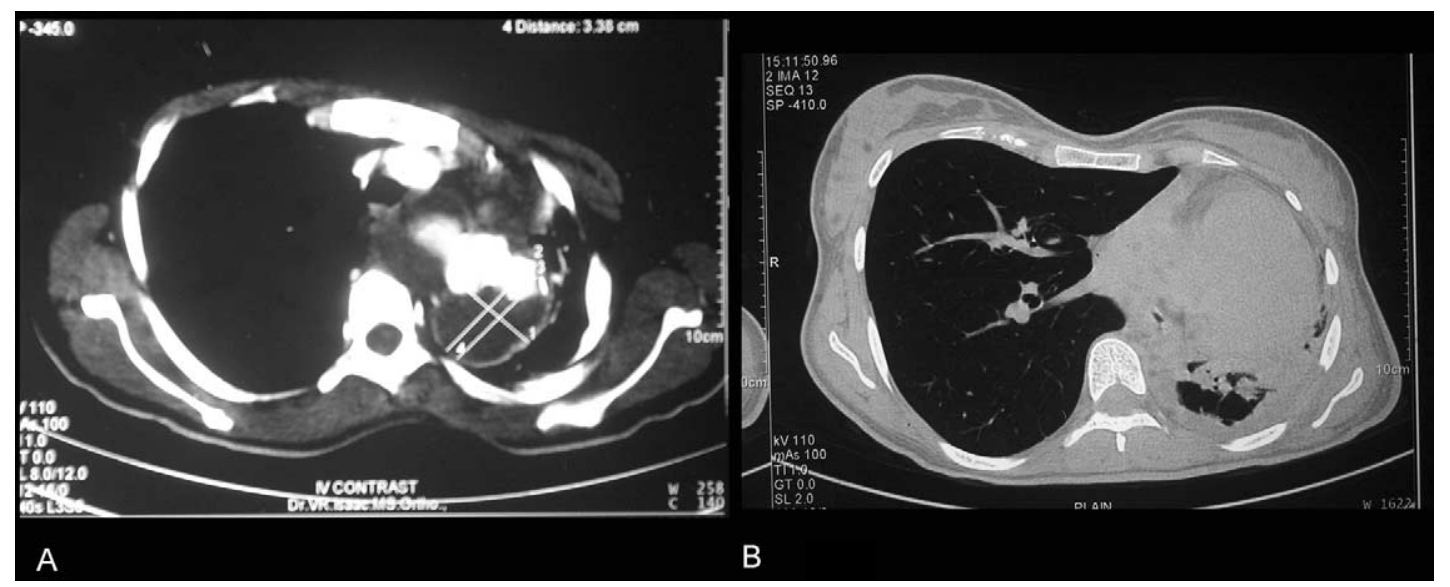

Figure 2. A, Computed tomographic scan of the chest showing a large aneurysm with thrombus. B, Computed tomographic scan lung window showing destroyed left lung.

experiences, ${ }^{4}$ and this causes degenerative changes in the flap (vessel wall). In addition, the normal atherosclerotic changes in human arteries predispose this area to aneurysm formation. ${ }^{5}$

The large aneurysm caused compression of the left main stem bronchus and lung parenchyma. Long-standing lung collapse results in fibrotic changes in parenchyma and in the overlying pleura that prevents lung inflation, ${ }^{6}$ and perhaps both mechanisms played a role in the destruction of the left lung.

Surgical management of these patients is a challenge because the aneurysm is adherent to the lung and the chest wall, with highly vascular tissue. Dissection of this area is extremely difficult, and most cases require extracorporeal circulation for repair. Nguyen and coworkers ${ }^{2}$ recommend that it is mandatory for patients who have undergone this procedure to be followed up yearly so that early detection and management can be instituted. Long-term follow-up is required because the risk of aneurysm formation increases with time.

In conclusion, patients who have undergone SFA are subject to a small but real risk of late aneurysm formation. Surgical repair is rendered difficult by the extensive adhesions between the aneurysm, lung, and chest wall.

\section{References}

1. Knyshov GV, Sitar LL, Glagola MD, Atamanyuk MY. Aortic aneurysms at the site of the repair of coarctation of aorta: a review of 48 patients. Ann Thorac Surg. 1996;61:935-9.

2. Nguyen DM, Tsang J, Tchervenkov CI. Aneurysm after subclavian flap angioplasty repair of coarctation of aorta. Ann Thorac Surg. 1999;68: $1392-4$.

3. Moulton AL, Brenner JI, Roberts G, Tavares S, Ali S, Nordenberg A, et al. Subclavian flap repair of coarctation of aorta in neonates: realization of growth potential? J Thorac Cardiovasc Surg. 1984;87:220-35.

4. Mellgren G, Friberg LG, Bjorkerud S. Can we predict the long-term function of the subclavian flap angioplasty? J Thorac Cardiovasc Surg. 1992;104:932-7.

5. McGiffin DC, McGiffin PB, Galbraith AJ, Cross RB. Aortic wall stress profile after repair of coarctation of the aorta. J Cardiovasc Thorac Surg. 1992;104:924-31.

6. Corrin B. The lungs. In: Corrin B, editor. Systemic pathology. New York: Churchill Livingstone; 1990. p. 161-5. 